\title{
In vitro virucidal activity of the theaflavin-concentrated tea extract TY-1 against influenza $A$ virus
}

\author{
Israa M. A. Mohamed ${ }^{1,2} \cdot$ Haruko Ogawa $^{3} \cdot$ Yohei Takeda $^{3,4}(\mathbb{C}$
}

Received: 17 May 2021 / Accepted: 8 September 2021 / Published online: 22 September 2021

(c) The Japanese Society of Pharmacognosy 2021

\begin{abstract}
The annual spread of influenza A virus (IAV) infection is a global concern. We examined the IAV-inactivating potential of theaflavin-concentrated tea extract TY-1, which contains abundant polyphenols, including concentrated theaflavins and catechins. TY-1 exhibited concentration- and time-dependent virucidal activity against IAV. Specifically, $5.0 \mathrm{mg} / \mathrm{mL} \mathrm{TY-1}$ induced a 1.33 and $\geq 5.17 \log _{10} 50 \%$ tissue culture infective dose/mL reduction of the viral titer compared with dextrin as the diluent control within $30 \mathrm{~min}$ and $6 \mathrm{~h}$ reaction time, respectively. The high virucidal activity of TY-1 was attributed to the combined additive activities of multiple virucidal components, including theaflavins, which led to an investigation of the virucidal mechanism of action of TY-1. Western blotting revealed that TY-1 treatment reduced the band intensity of hemagglutinin and induced the appearance of additional high molecular mass bands/ladders. In addition, TY-1 treatment also reduced the band intensity of neuraminidase (NA). A hemagglutination assay revealed that TY-1 reduced hemagglutination activity, and an NA assay revealed reduced NA activity. These results indicated that TY-1 caused structural abnormalities in IAV spike proteins, possibly leading to their destruction. Reverse transcription polymerase chain reaction (PCR) targeting the IAV genome and electron microscopic observation of viral particles revealed that upon application of TY-1, the PCR products dissipated, which indicates that TY-1 destroyed the IAV genome, and the number of viral particles reduced. Overall, TY-1 exhibited multiple modes of IAV-inactivating activity. Our findings support the possible future practical use of TY-1 as a virucidal supplemental agent that can contribute to IAV infection control.
\end{abstract}

Keywords Influenza A virus · Tea leaf-derived materials $\cdot$ Theaflavin-concentrated tea extract TY-1 $\cdot$ Virucidal activities

Yohei Takeda

ytakeda@obihiro.ac.jp

1 Graduate School of Animal and Veterinary Sciences and Agriculture, Obihiro University of Agriculture and Veterinary Medicine, 2-11 Inada, Obihiro, Hokkaido 080-8555, Japan

2 Department of Animal and Poultry Hygiene and Environmental Sanitation, Faculty of Veterinary Medicine, Assiut University, Assiut 71526, Egypt

3 Department of Veterinary Medicine, Obihiro University of Agriculture and Veterinary Medicine, 2-11 Inada, Obihiro, Hokkaido 080-8555, Japan

4 Research Center for Global Agromedicine, Obihiro University of Agriculture and Veterinary Medicine, 2-11 Inada, Obihiro, Hokkaido 080-8555, Japan

\section{Introduction}

Influenza A virus (IAV) is the only influenza virus type that causes pandemic, and it is also responsible for most influenza-related hospitalizations [1]. Within the last 100 years, the world has witnessed four pandemics of novel strains of IAV that caused 500,000-50 million deaths [2]. Effective prophylaxis and antiviral remedies are essential factors for controlling highly contagious diseases. One of the most efficient and common strategies for controlling infection is vaccination. However, because of antigenic drift and antigenic shift, IAV can evade the neutralizing activity of previously established antibodies, causing them to become ineffective against next-year infection [3]. Given this concept, other daily preventive measures appear essential for combating IAV infection. Such preventive measures usually involve recommended procedures such as wearing masks or hand washing [4]. Although hand washing is effective, it only removes viruses from the initial contact site, and it is more 
operative when other reagents that can disrupt viruses are used concomitantly. Several virucidal agents exist [5]; nevertheless, some of these chemical substances are toxic and corrosive, and they cause environmental pollution, thereby limiting their use as disinfectants for viruses on the human body and surfaces [6]. Several antiviral drugs exist for use. Even if therapeutic efficacy is elicited, the emergence of resistant viral strains is a matter of concern [7]. In addition, the side effects of some medicines have been reported [8]. Owing to the possible insufficient efficacy of currently available vaccines against novel strains, limitations of chemical virucidal agents, and the emergence of drug resistance, safe supportive interventions are required to prevent viral infection and worsening of severity.

The tea plant, Camellia sinensis, is an evergreen tree belonging to the family Theaceae, which is indigenous to China and Southeast Asia. The leaves of $C$. sinensis contain all the structures and standard enzymes associated with plant cell growth and photosynthesis. The harvested leaf can be treated with various methods to produce three main types of teas: green, black, or Oolong tea. Uniquely, the teas produced from this plant contain relatively large quantities of polyphenols $[9,10]$. Tea polyphenols have attracted the researcher's attention as natural substances and safe therapeutic options for many diseases. It was proven in cell culture that epigallocatechin (EGC), EGC gallate (EGCG), and epicatechin gallate (ECG) present in green tea could inhibit the replication of adenovirus and influenza virus [11-13]. Black tea, which comprises $78 \%$ of tea consumed worldwide [14], can be synthesized by crushing and rolling the withered leaves of $C$. sinensis, which are then fully fermented [15]. Black tea is rich in theaflavins (TFs), polyphenols that are produced via the enzymatic oxidation and dimerization of green tea catechins, and their anti-inflammatory [16], antimicrobial [17], and antiviral activities [16, 18, 19] have been reported. In a previous study, highly TF-concentrated tea extract powder TY-1 was produced from raw green tea leaves [20]. Briefly, fresh raw green tea leaves were added to water and green tea leaf extract; then, the leaves were crushed into a paste with a mixer. With this step, polyphenol oxidase, peroxidase, tannase, hydrolase, catechins, caffeine, and other components were released from the plant cells into the water. Then, the raw green tea leaves paste was gently stirred with minimum aeration for $10 \mathrm{~min}-8 \mathrm{~h}$, which promoted a reaction of various enzymes with components, thus resulting in the conversion of catechins into TFs and gallic acid production. The paste was then heated for sterilization, and the liquid layer was collected. TY-1 powder was produced by filtering and drying this liquid layer. By following this unique procedure, abundant and standardized TFs were obtained. The safety of TY-1 was confirmed by genotoxicity and mutagenicity tests such as the Ames test, micronucleus test, and comet assay. Accordingly, this study examined the virucidal effect of TY-1, which abundantly contains not only TFs but also other polyphenols, on IAV and elucidated its mechanism of action in an effort to introduce the substance as a promising supplement or alternative to the currently available antiviral therapies.

\section{Methods}

\section{Virus and cells}

IAV subtype H1N1 (A/Puerto Rico/8/1934 strain: ATCC $^{\circledR}$ Catalog No. VR-95TM) was obtained from ATCC (Manassas, VA, USA), then propagated via inoculation into the allantoic cavity of 10-day-old embryonated chicken eggs. Allantoic fluids containing IAV were used as viral solutions unless otherwise stated. To prepare purified IAV, which was used for some studies, sucrose gradient ultracentrifugation was performed as previously mentioned [21]. A Micro BCA protein assay kit (Thermo Fisher Scientific Inc., Waltham, MA, USA) was used to estimate the purified IAV protein concentration. Madin-Darby canine kidney (MDCK) cells were kindly provided by Dr. H. Nagano (Hokkaido Institute of Public Health, Sapporo, Japan). For MDCK cell culture, Dulbecco's modified Eagle's minimal essential medium (DMEM; Nissui Pharmaceutical Co., Ltd., Tokyo, Japan) supplemented with $10 \%$ fetal bovine serum, $2 \mathrm{mM}$ L-glutamine, $0.15 \% \mathrm{NaHCO}_{3}$ (FUJIFILM Wako Pure Chemical Co., Osaka, Japan), $2 \mu \mathrm{g} / \mathrm{mL}$ amphotericin B (Bristol-Myers Squibb Co., New York, NY, USA), and $100 \mu \mathrm{g} / \mathrm{mL}$ kanamycin (Meiji Seika Pharma Co., Ltd., Tokyo, Japan) was used as the growth medium. Following viral inoculation, viral growth medium consisted of DMEM supplemented with $0.2 \%$ bovine serum albumin, $0.15 \% \mathrm{NaHCO}_{3}, 0.01 \%$ glucose, $2.5 \mathrm{mM}$ HEPES, and $0.0006 \%$ trypsin (FUJIFILM Wako Pure Chemical Co.) was used for MDCK cell culture.

\section{Preparation of a TY-1 stock solution and other test solutions}

TY-1 powder was provided by Yokoyama Food Co., Ltd. (Sapporo, Japan). The components of TY-1 powder and their corresponding yields were analyzed by Eurofins Food Testing Japan, K.K (Shizuoka, Japan), and those are presented in Table 1. Specifically, the concentrations of TFs were analyzed by high-performance liquid chromatography; those of catechins, caffeine, theanine, and gallic acid were analyzed by liquid chromatography-tandem mass spectrometry method; those of total polyphenol and dietary fiber were analyzed by the Folin-Ciocalteu method and Prosky method, respectively. Chen et al. revealed the chemical structures of TFs and its derivatives [22]. To prepare TY-1 stock solution, $1 \mathrm{~g}$ of TY-1 powder was dissolved in $100 \mathrm{~mL}$ of 
Table 1 Composition of $10 \mathrm{mg}$ TY-1 powder

\begin{tabular}{lll}
\hline Item & & Value \\
\hline Total theaflavins (TFs) $(0.165 \mathrm{mg})$ & Theaflavin (TF1) & $0.112 \mathrm{mg}$ \\
& Theaflavin-3-gallate (TF2A) & $0.029 \mathrm{mg}$ \\
& Theaflavin-3'-gallate (TF2B) & $0.014 \mathrm{mg}$ \\
& Theaflavin-3,3'-digallate (TF3) & $0.010 \mathrm{mg}$ \\
Total catechin $(0.067 \mathrm{mg})$ & Epicatechin (EC) & $0.035 \mathrm{mg}$ \\
& Epigallocatechin (EGC) & $0.005 \mathrm{mg}$ \\
& Epigallocatechin gallate (EGCG) & $0.025 \mathrm{mg}$ \\
Caffeine & Epicatechin gallate (ECG) & $0.002 \mathrm{mg}$ \\
Theanine & & $0.180 \mathrm{mg}$ \\
Gallic acid & & $0.130 \mathrm{mg}$ \\
Total polyphenol & & $0.104 \mathrm{mg}$ \\
Dietary fiber & & $1.600 \mathrm{mg}$ \\
Dextrin & & $0.440 \mathrm{mg}$ \\
\hline
\end{tabular}

phosphate-buffered saline (PBS), followed by centrifugation $(9000 \times g$ for $10 \mathrm{~min})$. After centrifugation, the water-soluble layer was filtered using a $0.2 \mu \mathrm{m}$ syringe filter (Sartorius AG, Gottingen, Germany). The obtained solution was kept at $-80{ }^{\circ} \mathrm{C}$ until use. Because TY-1 powder contains $50 \%$ dextrin, dextrin solution prepared similarly as TY-1 solution was used as the diluent control. The measured $\mathrm{pH}$ was 6.8 and 7.1 for the TY-1 and dextrin solutions, respectively. The final concentrations of the TY-1 and dextrin stock solutions were 10 and $5 \mathrm{mg} / \mathrm{mL}$, respectively. A $0.165 \mathrm{mg} / \mathrm{mL}$ TFs solution was prepared by dissolving $0.112 \mathrm{mg}$ theaflavin (FUJIFILM Wako Pure Chemical Co), $0.043 \mathrm{mg}$ theaflavin3'-gallate (FUJIFILM Wako Pure Chemical Co), $0.010 \mathrm{mg}$ theaflavin-3,3'-digallate (FUJIFILM Wako Pure Chemical Co), and $5.000 \mathrm{mg}$ dextrin in $1 \mathrm{~mL}$ PBS. A $0.067 \mathrm{mg} / \mathrm{mL}$ catechins solution was prepared by dissolving $0.067 \mathrm{mg}$ catechin mixture from green tea (FUJIFILM Wako Pure Chemical Co) and $5.000 \mathrm{mg}$ dextrin in $1 \mathrm{~mL}$ PBS. A $0.232 \mathrm{mg} / \mathrm{mL}$ TFs + catechins solution was prepared by dissolving $0.112 \mathrm{mg}$ theaflavin, $0.043 \mathrm{mg}$ theaflavin-3'-gallate, $0.010 \mathrm{mg}$ theaflavin-3,3'-digallate, $0.067 \mathrm{mg}$ catechin mixture from green tea, and $5.000 \mathrm{mg}$ dextrin in $1 \mathrm{~mL}$ PBS.

\section{Evaluation of the virucidal activity of TY-1}

The virucidal activity of TY-1 against IAV was investigated as follows. Five concentrations of TY-1 and one concentration of dextrin solution were mixed with the viral solutions. The final concentrations of TY- 1 were $0.3,0.6,1.3,2.5$, and $5.0 \mathrm{mg} / \mathrm{mL}$ in the mixture. The concentration of dextrin used for the mixture was $2.5 \mathrm{mg} / \mathrm{mL}$. Additionally, one concentration each of the catechins solution, TFs solution, and TFs + catechins solution was mixed with the viral solution. In the mixture, the final concentrations of the catechins, TFs, and TFs + catechins were $0.034,0.083$, and $0.116 \mathrm{mg} / \mathrm{mL}$, respectively. The viral titer of the mixtures was adjusted to be approximately $7.45 \log _{10} 50 \%$ tissue culture infective dose $\left(\mathrm{TCID}_{50}\right) / \mathrm{mL}$. These mixtures were incubated at $25^{\circ} \mathrm{C}$ for different times (10 min, $30 \mathrm{~min}, 1 \mathrm{~h}, 3 \mathrm{~h}, 6 \mathrm{~h}, 24 \mathrm{~h}$ ). Following the incubation, the mixtures were inoculated into MDCK cells, and tenfold serial dilutions were performed. Three days later, the viral titers of the test solution-treated viruses were assessed by observing the cytopathic effects on the cells. The viral titer was calculated using the Behrens-Kärber method [23]. The differences in viral titer between the test solution-treated groups and the dextrin solution-treated groups represented the virucidal activity of each test solution. The detection limit of viral titers in each group was determined according to the cytotoxicity of each test solution in MDCK cells in a virus-free condition. As the dextrin, catechins, TFs, TFs + catechins, and $0.3,0.6$, and $1.3 \mathrm{mg} / \mathrm{mL}$ TY-1 groups did not exhibit cytotoxicity, the detection limit of the viral titer in these groups was set to $1.25 \log _{10}$ TCID $_{50} /$ $\mathrm{mL}$, according to our viral titer calculation. However, the 2.5 and $5.0 \mathrm{mg} / \mathrm{mL}$ TY-1 groups showed moderate cytotoxicity, and the detection limit in these groups was set to $2.25 \log _{10}$ $\mathrm{TCID}_{50} / \mathrm{mL}$.

\section{Sodium dodecyl sulfate-polyacrylamide gel electrophoresis (SDS-PAGE)}

The mixtures containing $6.58 \log _{10} \mathrm{TCID}_{50} / \mathrm{mL}_{\text {purified IAV }}$ and $5.0 \mathrm{mg} / \mathrm{mL}$ TY-1 or $2.5 \mathrm{mg} / \mathrm{mL}$ dextrin were incubated at $25{ }^{\circ} \mathrm{C}$ for $48 \mathrm{~h}$. Then, the mixtures were combined with a one-third volume of $4 \times$ SDS sample buffer with and without 2-mercaptoethanol (2-Me; FUJIFILM Wako Pure Chemical Co.). These samples were applied to SDS-PAGE, and then Coomassie brilliant blue (CBB) staining or western blotting (WB) was performed as previously described [24]. For WB to detect IAV hemagglutinin (HA), rabbit anti-H1N1 
(A/Puerto Rico/8/34) HA polyclonal antibody (Catalog No. 11684-T62, Sino Biological Inc., Beijing, China) and mouse anti-rabbit IgG peroxidase conjugate (Catalog No. A1949, Clone: RG-96, Sigma-Aldrich, Inc., St. Louis, MO, USA) were used as the primary and secondary antibodies, respectively. For WB to detect IAV neuraminidase (NA), rabbit anti-H1N1 NA (Catalog No. GTX125974, Gentex Inc., Zeeland, MI, USA) and mouse anti-rabbit IgG peroxidase conjugate were used as the primary and secondary antibodies, respectively.

\section{Hemagglutination and NA assays}

The mixtures containing $7.25 \log _{10} \mathrm{TCID}_{50} / \mathrm{mL}$ purified IAV and $5.0 \mathrm{mg} / \mathrm{mL}$ TY-1 or $2.5 \mathrm{mg} / \mathrm{mL}$ dextrin were incubated at $25^{\circ} \mathrm{C}$ for $48 \mathrm{~h}$. Thereafter, the hemagglutination and NA assays were performed in line with the WHO manual on animal influenza diagnosis and surveillance [25].

\section{Reverse transcription-polymerase chain reaction (RT-PCR)}

The mixtures containing $7.25 \log _{10} \mathrm{TCID}_{50} / \mathrm{mL}$ purified IAV and $5.0 \mathrm{mg} / \mathrm{mL}$ TY- 1 or $2.5 \mathrm{mg} / \mathrm{mL}$ dextrin were incubated at $25^{\circ} \mathrm{C}$ for $48 \mathrm{~h}$. After the incubation, RNA extraction and RT-PCR were performed as previously mentioned [24]. The sequence of primers targeting the IAV M gene used and each PCR condition are presented in Supplementary Table 1.

\section{Transmission electron microscopy (TEM)}

The mixtures containing $6.58 \log _{10} \mathrm{TCID}_{50} / \mathrm{mL}$ purified IAV and $5.0 \mathrm{mg} / \mathrm{mL}$ TY- 1 or $2.5 \mathrm{mg} / \mathrm{mL}$ dextrin were incubated at $25{ }^{\circ} \mathrm{C}$ for $48 \mathrm{~h}$. A two-step protocol [21] was followed in which TEM samples were loaded on a 400-mesh carboncoated collodion grid (NISSHIN EM Co., Ltd., Tokyo, Japan). On the grids, by using $2 \%$ phosphotungstic acid (pH $6.5)$, the treated viruses were negatively stained for $2 \mathrm{~min}$. Then, the samples were examined using TEM (HT7700; Hitachi High-Tech Co., Tokyo, Japan).

\section{Statistical analysis}

Student's $t$ test was used to determine statistically significant differences between the dextrin and TY-1 groups in each conducted experiment to evaluate viral and hemagglutination titers. One-way analysis of variance (ANOVA), followed by Tukey's post hoc test were used to determine statistically significant differences among the viral titers of the dextrin, catechins, TFs, TFs + catechins, and TY-1 groups. $P$ values less than 0.05 indicated the existence of significant difference between the selected items.

\section{Results}

\section{Virucidal efficacy of TY-1 against IAV}

First, the virucidal activities of different concentrations of TY-1 against IAV were evaluated. As a result, all tested concentrations $(0.3,0.6,1.3,2.5,5.0 \mathrm{mg} / \mathrm{mL})$ of TY-1 exhibited statistically significant IAV-inactivating activities within $24 \mathrm{~h}$, and these activities were concentrationand time-dependent. The TY-1 concentration of $5.0 \mathrm{mg} /$ $\mathrm{mL}$ displayed statistically significant virucidal activity within $30 \mathrm{~min}$ (a $1.33 \log _{10} \mathrm{TCID}_{50} / \mathrm{mL}$ reduction of the viral titer compared to the dextrin group). The viral titer in this group was below the detection limit in $6 \mathrm{~h}(\geq 5.17$ $\log _{10} \mathrm{TCID}_{50} / \mathrm{mL}$ reduction) (Fig. 1a). The $5.0 \mathrm{mg} / \mathrm{mL}$ TY- 1 contained $0.034 \mathrm{mg} / \mathrm{mL}$ catechins and $0.083 \mathrm{mg} / \mathrm{mL}$ TFs (Table 1). To evaluate the contribution of catechins and TFs, which are two of the main virucidal components of TY-1, to IAV inactivation, virucidal activity of $5.0 \mathrm{mg} /$ $\mathrm{mL}$ TY- 1 was compared to that of the $0.034 \mathrm{mg} / \mathrm{mL}$ catechins solution, $0.083 \mathrm{mg} / \mathrm{mL}$ TFs solution, and $0.116 \mathrm{mg} /$ $\mathrm{mL}$ TFs + catechins solution. The viral titers of the dextrin, catechins, TFs, TFs + catechins, and TY-1 groups were $6.88,6.56,5.88,5.88$, and $\geq 3.06 \log _{10} \mathrm{TCID}_{50} / \mathrm{mL}$, respectively, within $3 \mathrm{~h}$. Additionally, the viral titers of the dextrin, catechins, TFs, TFs + catechins, and TY-1 groups were $6.13,5.94,4.88,4.38$, and $\geq 2.25 \log _{10} \mathrm{TCID}_{50} / \mathrm{mL}$, respectively, within $24 \mathrm{~h}$. With this reaction time, the viral titer of the TFs group was partially lower than that of the dextrin group, but that of the TY-1 group was below the detection limit. Although the viral titer of the catechins group was comparable to that of the dextrin group, that of the TFs + catechins group was slightly but significantly lower than that of the TFs group (Fig. 1b). The $5.0 \mathrm{mg} / \mathrm{mL}$ TY-1 treatment, which exhibited the strongest virus-inactivating activity, was further tested against IAV to fully illustrate the mechanism of its virucidal activity.

\section{Impact of TY-1 on IAV proteins}

The impacts of the TY-1 treatment on the functions and structures of IAV structural proteins were analyzed. Here, purified IAV was used to eliminate the influence of nonviral proteins. After treatment with $5.0 \mathrm{mg} / \mathrm{mL}$ TY-1 for $48 \mathrm{~h}$, the viral titers decreased to below the detection limit compared to that in the dextrin group (Fig. 2a). The impact of the TY- 1 treatment under the same conditions on the hemagglutination activity of the HA protein was evaluated by a hemagglutination assay. The hemagglutination titer of IAV treated with $5.0 \mathrm{mg} / \mathrm{mL}$ TY- 1 for $48 \mathrm{~h}$ was significantly lower than that of the dextrin group (Fig. 2b). 

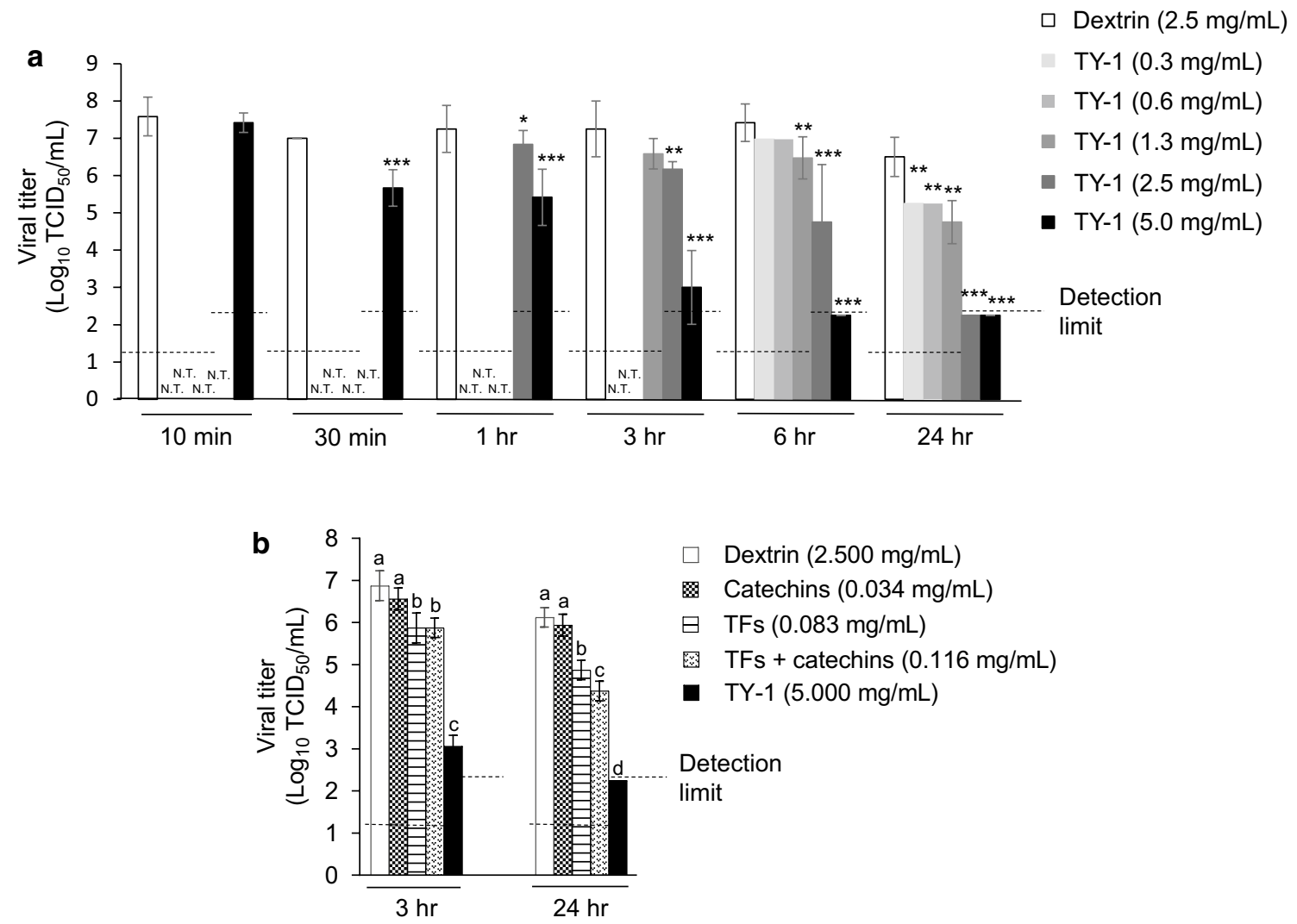

Fig. 1 Evaluation of the virucidal activity of TY-1 at different concentrations and exposure periods. a, b Dextrin $(2.5 \mathrm{mg} / \mathrm{mL})$ was used as a solvent control. The results are indicated as the mean $\pm \mathrm{SD}(n>4$ per group). a Student's $t$-test was performed to analyze statistical differences between the dextrin group and each TY-1 group: $* p<0.05$,

Subsequently, the impacts of TY-1 on the structures of viral proteins were analyzed via SDS-PAGE. As a result, CBB staining showed reduced intensity for some viral protein bands for TY-1-treated IAV. Such changes were observed for the viral HA0 protein detected in the absence of 2-Me and for HA1 and HA2 in the presence of 2-Me, and all changes were tentatively recognized according to their apparent molecular mass. Contrarily, the intensities of bands which were presumed to be the M1 and NP proteins were not affected by TY-1 exposure (Fig. 2c). To further evaluate the impact of TY-1 on viral HA proteins, WB was achieved using a primary antibody that detects the HA protein of IAV. In line with the CBB staining results, TY-1 treatment strongly reduced the intensity of the $\sim 60 \mathrm{kDa}$ HA0 protein band. Additionally, the intensities of additional $>75 \mathrm{kDa}$ bands/ladder were stronger under the TY-1 treatment than the dextrin treatment (Fig. 2d-left). While the intensities of the HA1 and HA2 bands were weaker under the TY-1 treatment than the dextrin treatment, the intensities of additional bands/ladder with a higher
$* * p<0.001, * * * p<0.001$. N.T.: not tested. b One-way analysis of variance (ANOVA) followed by Tukey's post hoc test were performed to analyze statistical differences among all test solution groups; test solution groups that do not share a common letter were significantly different $(* p<0.05)$

molecular mass were stronger under the TY-1 treatment than the dextrin treatment (Fig. 2d-right). Meanwhile, the effect of TY-1 on the NA activity and quality of the NA protein were analyzed by NA assay and WB, respectively. TY-1-treated IAV displayed substantially lower NA activity than dextrin-treated IAV (Fig. 3a). Accordingly, the results of WB using an antibody against the NA protein of IAV revealed disappearance of the NA protein band in TY-1-treated IAV, whereas it was clearly identified in dextrin-treated IAV (Fig. 3b).

\section{Impact of TY-1 on the IAV genome}

The impact of TY-1 on the IAV genome was explored via RT-PCR, in which primers were designed to amplify three different regions of the IAV M gene and produce amplicons of different lengths. After $48 \mathrm{~h}$ of treatment with $5.0 \mathrm{mg} / \mathrm{mL}$ TY-1, no PCR products were detected, unlike the results for dextrin-treated IAV (Fig. 4). 

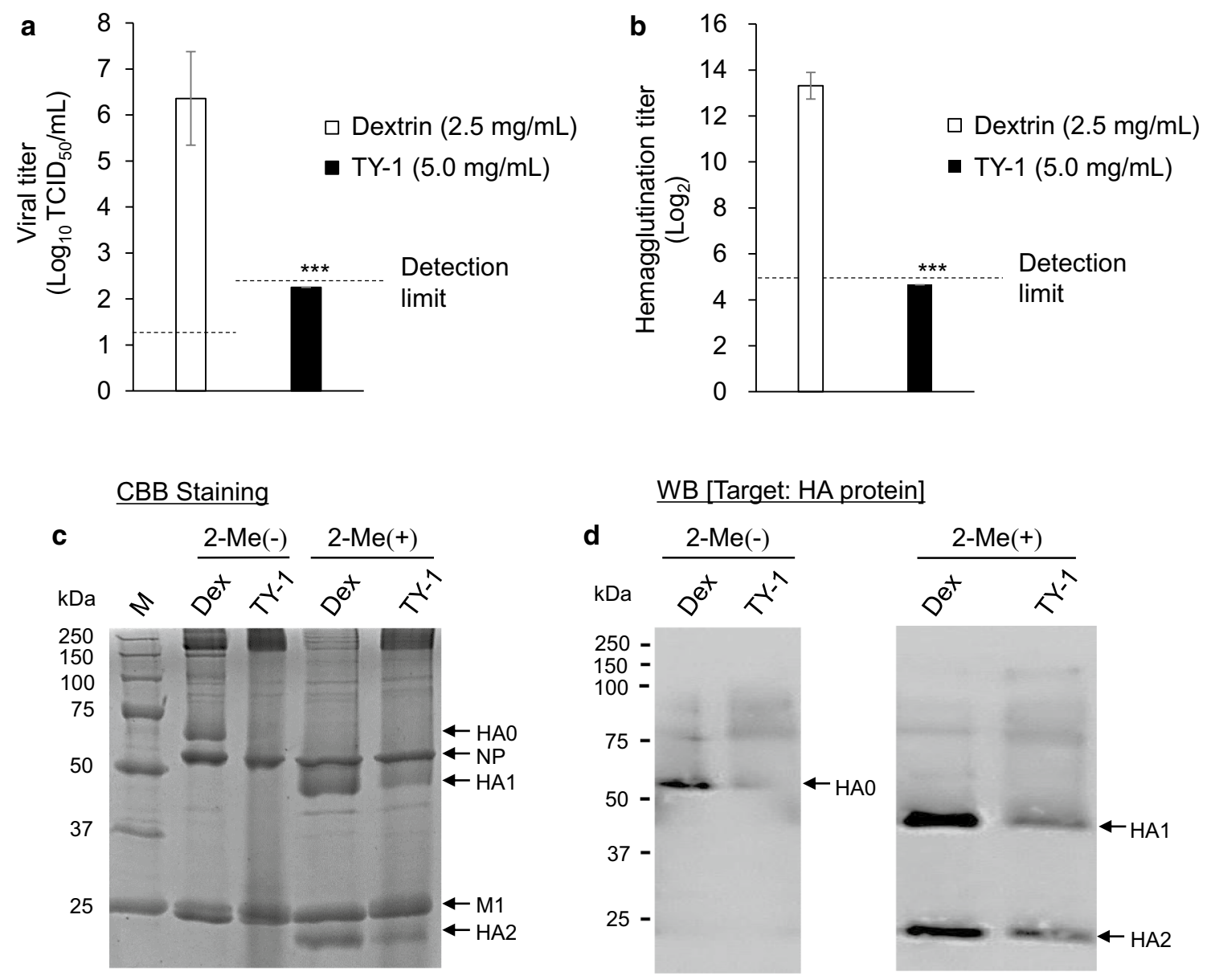

Fig. 2 Evaluation of the effect of TY-1 on influenza A virus (IAV) hemagglutinin (HA) proteins. Dextrin (Dex) and TY-1 were mixed with a solution containing purified IAV and stored at $25^{\circ} \mathrm{C}$ for $48 \mathrm{~h}$. a The viral titer of the mixture was evaluated. The results are presented as the mean \pm SD ( $n=3$ per group). b The hemagglutination titer of the mixture was evaluated. The results are presented as the mean \pm SD ( $n=3$ per group). Student's $t$ test was performed to analyze statistical differences between the dextrin and TY-1 groups:

$* * * p<0.001$. c Coomassie brilliant blue (CBB) staining of the gel from sodium dodecyl sulfate-polyacrylamide gel electrophoresis (SDS-PAGE). 2-Me: 2-mercaptoethanol, M: Marker. d Results of western blotting (WB) to detect IAV HA proteins. c, d To evaluate the bands of HA0 or HA1/HA2, SDS-PAGE without or with 2-Me was performed, respectively. The results are representatives of three individual experiments

Fig. 3 Evaluation of the effect of TY-1 on influenza A virus (IAV) neuraminidase (NA). Dextrin (Dex) and TY-1 were mixed with a solution containing purified IAV and stored at $25^{\circ} \mathrm{C}$ for $48 \mathrm{~h}$. a The NA activity of the mixture was evaluated. The results are indicated as the mean $\pm \mathrm{SD}(n=3$ per group). $\mathbf{b}$ Results of western blotting (WB) to detect IAV NA. The results represent two independent experiments

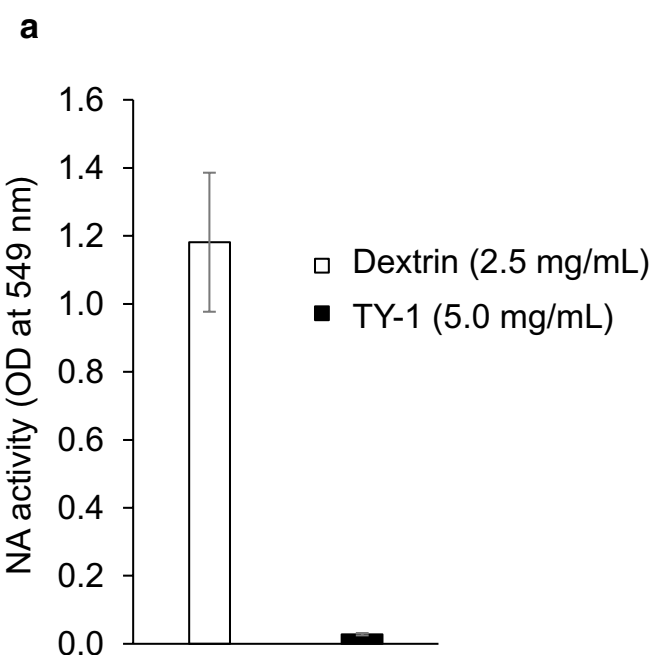

\section{b WB [Target: NA protein]}

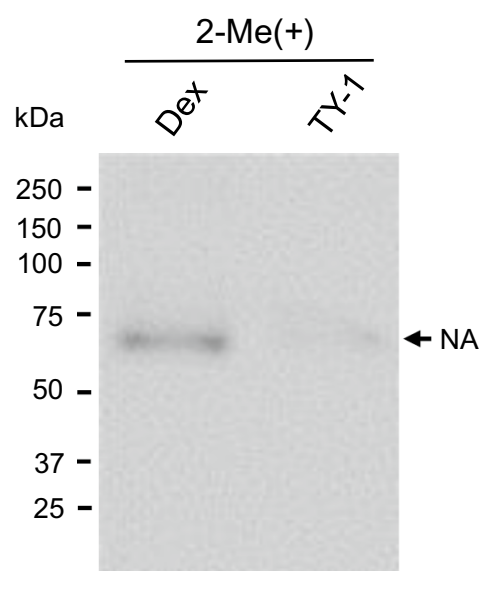




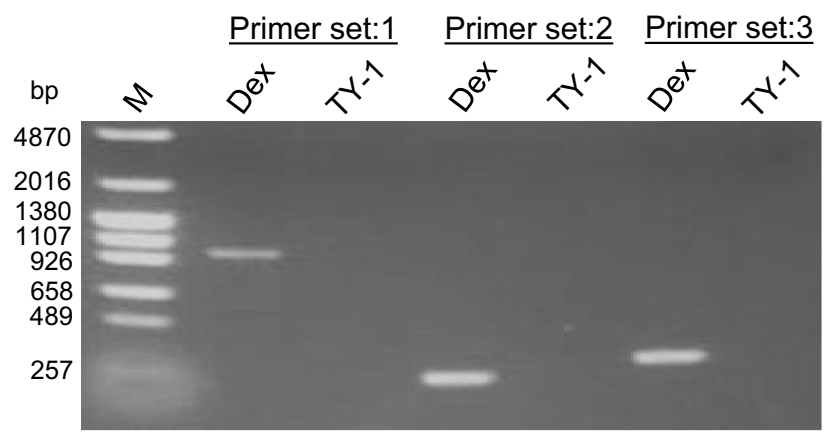

Fig. 4 Effect of TY-1 on the influenza A virus (IAV) genome. Dextrin (Dex) and TY-1 were mixed with a solution containing purified IAV and stored at $25{ }^{\circ} \mathrm{C}$ for $48 \mathrm{~h}$. The viral RNA extracted from the treated viruses was used for reverse transcription-polymerase chain reaction (RT-PCR). RT-PCR was performed using IAV-Primer sets 1, 2, and 3, which amplify 982-, 253-, and 320-bp of the IAV M gene, respectively. The results are representatives of more than two individual experiments. M: marker

\section{TEM analysis}

To analyze whether the TY-1 treatment induced abnormalities of the viral particle structure and a reduction in the particle numbers, TEM observation of IAV particles treated with $5.0 \mathrm{mg} / \mathrm{mL}$ TY-1 for $48 \mathrm{~h}$ was performed. Although abnormalities of TY-1-treated viral particles were not observed compared to dextrin-treated viral particles, the number of virions drastically decreased under TY-1 treatment compared to those under the effects of dextrin exposure to IAV (Fig. 5a, b).

\section{Discussion}

Natural products have been tested as alternatives to conventional treatments for various diseases in recent decades. Among natural products, medicinal plants can provide safe and effective therapies for many diseases [26, 27]. Among promising plants extracts, tea might be the most extensively consumed beverage globally with a rich historical background [28]. The virucidal activity of TY-1 was concentration- and time-dependent, which was in line with the results of Ohba et al. [29], who reported the effectiveness of TFs against caliciviruses. TY- 1 contains not only abundant TF derivatives, catechins, and gallic acid, but also a high amount of other polyphenols. Although TY-1 contains caffeine and theanine (Table 1), the virucidal activity of caffeine against an enveloped virus has not been observed [30], and there have been no reports proving obvious virucidal activity of theanine. Conversely, polyphenols, especially TFs and catechins, are widely reported to have virucidal activities against various types of viruses [12, 29, 31-34]. Here, our results revealed that TFs partially contributed to a

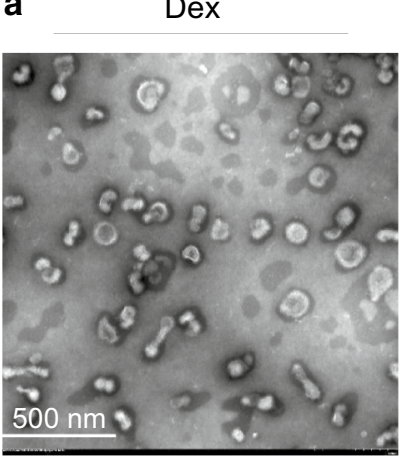

b

TY-1

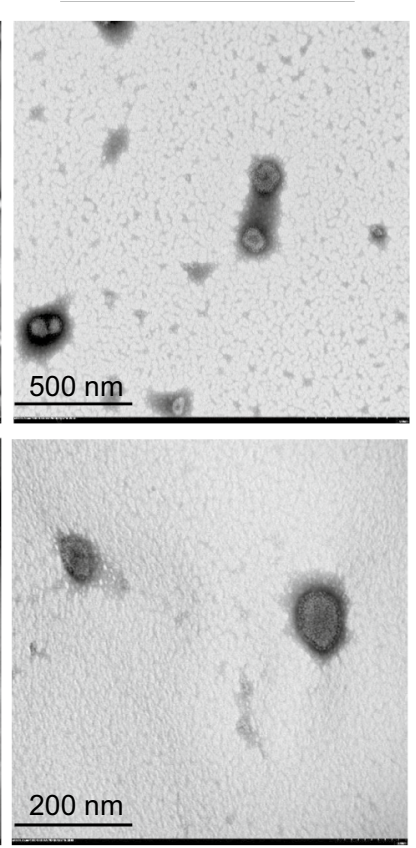

Fig. 5 Transmission electron microscopy (TEM) of TY-1-treated influenza A virus (IAV) virions. Dextrin (a) and TY-1 (b) were mixed with a solution containing purified IAV and stored at $25^{\circ} \mathrm{C}$ for $48 \mathrm{~h}$. After treatment, the viral particles were observed using TEM. The results are representative of dextrin- and TY-1-treated viral particles within a single $6.25 \mu \mathrm{m}^{2}$ field (upper panel) and $0.52 \mu \mathrm{m}^{2}$ field (lower panel), respectively

the virucidal activity of crude TY-1. Meanwhile, additive IAV inactivation was observed under the TFs + catechins treatment compared to that under TF treatment alone, and the contribution of catechins to IAV inactivation was limited (Fig. 1b). This result suggests that TFs are active compounds in TY-1, but other multiple virucidal polyphenolic compounds, such as catechins, contribute to the comprehensive virucidal activity of TY-1. Since it is expensive to prepare large quantities of pure TFs and other compounds with similar bioactive levels of TY-1, the application of TY-1 might be a more realistic approach to IAV infection control.

The results for the hemagglutination and NA assays and SDS-PAGE in the current study indicated the disruption of both the HA and NA proteins of IAV (Figs. 2 and 3, respectively). Particularly, the target sites of TY-1 in the HA and NA proteins included regions that are involved in hemagglutination activity and NA activity, which may be involved in the virucidal activity of TY-1. The impact of TY- 1 on the HA protein is consistent with previous reports in which TF, EGCG, and ECG affected hemagglutination activity of IAV $[12,13,16]$. Similarly, the impact of TY-1 on the NA protein is also consistent with previous reports in which the antiviral activity of TF, EGCG, and ECG on IAV was attributed to NA inhibition $[13,16,35]$. As a result of WB targeting HA 
protein, the TY-1-induced reduction of the band intensity of HA0, which consists of HA1 and HA2 subunits, seemed to be greater than the reduction of the band intensities of individual HA1 and HA2 subunits. Additionally, TY-1 treatment enhanced the appearance of high molecular mass bands/ladders (Fig. 2d). These bands/ladders are considered HA multimers or HA aggregates. Similar appearances among high molecular mass bands/ladders of the viral spike protein have been observed via another polyphenolic compound treatment [36]. Polyphenols have been reported to interact with proteins in both covalent and non-covalent interactions, which induces the cross-linking of proteins and formation of a high molecular mass complex [37]. Hence, our results suggest that polyphenolic compounds in TY-1 possibly interact with some sites in both HA1 and HA2 subunits, which caused the aggregation of these proteins. Therefore, the reduction of the band intensity of HA0, which has multiple sites of action located in both HA1 and HA2 subunits, may have been greater than those of individual subunits. Conversely, while the NA band almost disappeared after TY-1 treatment, high molecular band/ladders did not appear (Fig. 3b). This result suggests that TY-1 induces not only the aggregation of viral proteins but also their destruction. Discrepancies in the band patterns of TY-1-treated HA and NA proteins can be due to differences in their amino acid sequences and secondary/tertiary structures.

In addition, TEM analysis performed in this study revealed a substantial decrease in the number of IAV particles after TY-1 treatment, suggesting that TY-1 damages the morphology of virions and subsequently inhibits viral adsorption onto and penetration into host cells. It was also found that TY-1 disrupted viral genomes. This result agrees with previous reports that demonstrated other polyphenol-rich plant-derived extracts that induced the viral RNA destruction against multiple virus species [24, 36]. Our findings suggest that the virucidal activity of TY-1 could be attributable to several factors rather than a single mechanism. It has been mentioned that the number of galloyl groups on the chemical structure of TF and catechins appears to be directly related to their antiviral activities [13, $18,38]$. In addition, the hydroxyl groups of TFs are reportedly more important than the galloyl groups for antiviral activity against caliciviruses [29].

TY-1, with which the abundant polyphenol content, may be applicable as an antiviral mouthwash or troche. This idea is supported by previous reports that gargling with green tea and black tea extract decreased the incidence of influenza virus infection [39-41]. In addition, Lee et al. [42] found that water and diet comprising green tea components suppressed influenza virus replication in animal experiments. Although our efforts in this study only focused on the direct virucidal activity of TY-1, further studies evaluating the anti-IAV activity of TY-1 in infected cells, animals, and patients are also important to clarify its effectiveness for IAV control measures. These studies may support the idea that the practical use of virucidal supplements developed from TY-1 for the control of IAV infection.

\section{Conclusion}

In conclusion, this study revealed the concentration- and time-dependent IAV-inactivating activity of TY-1 enriched with tea-derived TF derivatives and other virucidal polyphenols. Of note, TY-1 disrupted the IAV spike proteins and genome and destroyed viral particles. We anticipate that these findings support the promise of TY-1 as a virucidal supplement that contributes to the control of IAV infection.

Supplementary Information The online version contains supplementary material available at https://doi.org/10.1007/s11418-021-01568-0.

Acknowledgements We thank Ms. Sachiko Matsuda and Dr. Dulamjav Jamsransuren for their technical assistance. We are grateful to Yokoyama Food Co., Ltd. (Sapporo, Japan) for providing TY-1 powder; Dr. H. Nagano (Hokkaido Institute of Public Health, Sapporo, Japan) for providing MDCK cells. We would like to thank Enago (https://www. enago.jp) for English language editing.

Authors contributions IMAM and YT designed and conceived the experiments. IMAM performed the experiments. IMAM, HO, and YT analyzed the data. IMAM, HO, and YT contributed to writing the manuscript. All authors checked and approved the final manuscript.

Funding This study was supported in part by Grants-in-Aid for Regional R\&D Proposal-Based Program from Northern Advancement Center for Science \& Technology of Hokkaido Japan. This work was also supported in part by the World-leading Innovative and Smart Education (WISE) Program (1801) from the Ministry of Education, Culture, Sports, Science, and Technology, Japan.

\section{Declarations}

Conflict of interest The authors declare no conflict of interest.

\section{References}

1. WHO. Influenza (Seasonal) (2020) https://www.who.int/newsroom/fact-sheets/detail/influenza-(seasonal). Accessed 6 Sept 2020

2. Saunders-Hastings PR, Krewski D (2016) Reviewing the history of pandemic influenza: understanding patterns of emergence and transmission. Pathogens 5:66

3. Scorza FB, Tsvetnitsky V, Donnelly JJ (2016) Universal influenza vaccines: shifting to better vaccines. Vaccine 34:2926-2933

4. Aiello AE, Murray GF, Perez V, Coulborn RM, Davis BM, Uddin $M$ et al (2010) Mask use, hand hygiene, and seasonal influenzalike illness among young adults: a randomized intervention trial. J Infect Dis 201:491-498

5. Grayson ML, Melvani S, Druce J, Barr IG, Ballard SA, Johnson PDR et al (2009) Efficacy of soap and water and alcohol-based 
hand-rub preparations against live H1N1 influenza virus on the hands of human volunteers. Clin Infect Dis 48:285-291

6. De Benedictis P, Beato MS, Capua I (2007) Inactivation of avian influenza viruses by chemical agents and physical conditions: a review. Zoonoses Public Health 54:51-68

7. Omoto S, Speranzini V, Hashimoto T, Noshi T, Yamaguchi H, Kawai $\mathrm{M}$ et al (2018) Characterization of influenza virus variants induced by treatment with the endonuclease inhibitor baloxavir marboxil. Sci Rep 8:1-15

8. Morimoto K, Nagaoka K, Nagai A, Kashii H, Hosokawa M, Takahashi $\mathrm{Y}$ et al (2015) Analysis of a child who developed abnormal neuropsychiatric symptoms after administration of oseltamivir: a case report. BMC Neurol 15:1-5

9. Balentine DA (1992) Manufacturing and chemistry of tea. In: Phenolic compounds in food and their effects on health I, chap 8, pp 102-117

10. Mahmood T, Akhtar N, Khan BA (2010) The morphology, characteristics, and medicinal properties of Camellia sinensis tea. $\mathrm{J}$ Med Plants Res 4:2028-2033

11. Weber JM, Ruzindana-Umunyana A, Imbeault L, Sircar S (2003) Inhibition of adenovirus infection and adenain by green tea catechins. Antivir Res 58:167-173

12. Nakayama M, Suzuki K, Toda M, Okubo S, Hara Y, Shimamura $\mathrm{T}$ (1993) Inhibition of the infectivity of influenza virus by tea polyphenols. Antivir Res 21:289-299

13. Song J-M, Lee K-H, Seong B-L (2005) Antiviral effect of catechins in green tea on influenza virus. Antivir Res 68:66-74

14. Yang CS, Lambert JD, Sang S (2009) Antioxidative and anticarcinogenic activities of tea polyphenols. Arch Toxicol 83:11-21

15. Lin J, Lin-Shiau S (2006) Mechanisms of hypolipidemic and antiobesity effects of tea and tea polyphenols. Mol Nutr Food Res 50:211-217

16. Zu M, Yang F, Zhou W, Liu A, Du G, Zheng L (2012) In vitro anti-influenza virus and anti-inflammatory activities of theaflavin derivatives. Antivir Res 94:217-224

17. Friedman M (2007) Overview of antibacterial, antitoxin, antiviral, and antifungal activities of tea flavonoids and teas. Mol Nutr Food Res 51:116-134

18. Liu S, Lu H, Zhao Q, He Y, Niu J, Debnath AK et al (2005) Theaflavin derivatives in black tea and catechin derivatives in green tea inhibit HIV-1 entry by targeting gp41. Biochim Biophys Acta (BBA) Gen Subj 1723:270-281

19. Cantatore A, Randall SD, Traum D, Adams SD (2013) Effect of black tea extract on herpes simplex virus-1 infection of cultured cells. BMC Complement Altern Med 13:139

20. Takemoto M (2011) Manufacturing method for Theaflavins using raw tea leaves. Japanese Patent No 4817206

21. Imai K, Ogawa H, Bui VN, Inoue H, Fukuda J, Ohba $M$ et al (2012) Inactivation of high and low pathogenic avian influenza virus $\mathrm{H} 5$ subtypes by copper ions incorporated in zeolite-textile materials. Antivir Res 93:225-233

22. Chen H, Hayek S, Guzman JR, Gillitt ND, Ibrahim SA, Jobin C et al (2012) The microbiota is essential for the generation of black tea theaflavins-derived metabolites. PLoS ONE 7:e51001

23. Kärber G (1931) Beitrag zur kollektiven behandlung pharmakologischer reihenversuche. Naunyn Schmiedebergs Arch Exp Pathol Pharmakol 162:480-483

24. Takeda Y, Murata T, Jamsransuren D, Suganuma K, Kazami Y, Batkhuu J et al (2020) Saxifraga spinulosa-derived components rapidly inactivate multiple viruses including SARS-CoV-2. Viruses 12:699

25. WHO (2002) WHO manual on animal influenza diagnosis and surveillance. https://www.who.int/csr/resources/publications/influ enza/whocdscsrncs5rev.pdf. Accessed 4 March 2021

26. Dattner AM (2003) From medical herbalism to phytotherapy in dermatology: back to the future. Dermatol Ther 16:106-113
27. Pan S-Y, Zhou S-F, Gao S-H, Yu Z-L, Zhang S-F, Tang M-K et al (2013) New perspectives on how to discover drugs from herbal medicines: CAM's outstanding contribution to modern therapeutics. Evid Based Complement Altern Med. https://doi. org/10.1155/2013/627375

28. Martin LC, Cooper R (2011) From herbs to medicines: a world history of tea-from legend to healthy obsession. Altern Complement Ther 17:162-168

29. Ohba M, Oka T, Ando T, Arahata S, Ikegaya A, Takagi H et al (2017) Antiviral effect of theaflavins against caliciviruses. J Antibiot (Tokyo) 70:443-447

30. Utsunomiya H, Ichinose M, Uozaki M, Tsujimoto K, Yamasaki H, Koyama AH (2008) Antiviral activities of coffee extracts in vitro. Food Chem Toxicol 46:1919-1924

31. Clark KJ, Grant PG, Sarr AB, Belakere JR, Swaggerty CL, Phillips TD et al (1998) An in vitro study of theaflavins extracted from black tea to neutralize bovine rotavirus and bovine coronavirus infections. Vet Microl 63:147-157

32. Chowdhury P, Sahuc ME, Rouillé Y, Rivière C, Bonneau N, Vandeputte A et al (2018) Theaflavins, polyphenols of black tea, inhibit entry of hepatitis C virus in cell culture. PLoS ONE 13:e0198226

33. Lee YH, Jang YH, Kim YS, Kim J, Seong BL (2018) Evaluation of green tea extract as a safe personal hygiene against viral infections. J Biol Eng 12:1-10

34. Ohgitani E, Shin-Ya M, Ichitani M, Kobayashi M, Takihara T, Kawamoto $\mathrm{M}$ et al (2021) Significant inactivation of SARS-CoV-2 in vitro by a green tea catechin, a catechin-derivative, and black tea galloylated theaflavins. Molecules 26:3572

35. Müller P, Downard KM (2015) Catechin inhibition of influenza neuraminidase and its molecular basis with mass spectrometry. J Pharm Biomed Anal 111:222-230

36. Takeda Y, Jamsransuren D, Matsuda S, Crea R, Ogawa H (2021) The SARS-CoV-2-inactivating activity of hydroxytyrosol-rich aqueous olive pulp extract (HIDROX ${ }^{\circledR}$ ) and its use as a virucidal cream for topical application. Viruses 13:232

37. Ozdal T, Yalcinkaya IE, Toydemir G, Capanoglu E (2019) Polyphenol-protein interactions and changes in functional properties and digestibility. Ref Modul Food Sci 2:566-577

38. Quosdorf S, Schuetz A, Kolodziej H (2017) Different inhibitory potencies of oseltamivir carboxylate, zanamivir, and several tannins on bacterial and viral neuraminidases as assessed in a cell-free fluorescence-based enzyme inhibition assay. Molecules 22:1989

39. Iwata M, Toda M, Nakayama M, Tsujiyama H, Endo W, Takahashi O et al (1997) Prophylactic effect of black tea extract as gargle against influenza. Kansenshogaku Zasshi 71:487-494

40. Yamada H, Takuma N, Daimon T, Hara Y (2006) Gargling with tea catechin extracts for the prevention of influenza infection in elderly nursing home residents: a prospective clinical study. J Altern Complement Med 12:669-672

41. Ide K, Yamada H, Matsushita K, Ito M, Nojiri K, Toyoizumi K et al (2014) Effects of green tea gargling on the prevention of influenza infection in high school students: a randomized controlled study. PLoS ONE 9:e96373

42. Lee HJ, Lee YN, Youn H-N, Lee DH, Kwak JH, Seong BL et al (2012) Anti-influenza virus activity of green tea by-products in vitro and efficacy against influenza virus infection in chickens. Poult Sci 91:66-73

Publisher's Note Springer Nature remains neutral with regard to jurisdictional claims in published maps and institutional affiliations. 